\title{
The Value of Metacognitive Skills and Intrinsic Motivation for Current and Future Sport Performance Level in Talented Youth Athletes
}

\author{
Floor Stam, Sofia Kouzinou, Chris Visscher, Marije T. Elferink-Gemser* (1) \\ Department of Human Movement Sciences, University Medical Center Groningen, University of Groningen, Groningen, The Netherlands \\ Email: *m.t.elferink-gemser@umcg.nl
}

How to cite this paper: Stam, F., Kouzinou, S., Visscher, C., \& Elferink-Gemser, M.T. (2020). The Value of Metacognitive Skills and Intrinsic Motivation for Current and Future Sport Performance Level in Talented Youth Athletes. Psychology, 11, 326-339.

https://doi.org/10.4236/psych.2020.112021

Received: November 14, 2019

Accepted: February 17, 2020

Published: February 20, 2020

Copyright $\odot 2020$ by author(s) and Scientific Research Publishing Inc. This work is licensed under the Creative Commons Attribution International License (CC BY 4.0).

http://creativecommons.org/licenses/by/4.0/

\begin{abstract}
Purpose: In order to spend training time efficiently, insight in factors that relate to the development of sport performance is highly relevant for competitive athletes and their trainers/coaches. Purpose is to unravel the value of metacognitive skills (MCS) and intrinsic motivation for current and future sport performance level. Methods: Talented youth athletes $(n=103)$ active in field hockey, basketball and soccer filled in questionnaires for IM and MCS. Level of sport performance was expressed by an adjusted version of the formula for Eliteness of Swann et al. (2015). Correlations between IM, MCS and current sport performance level were calculated and followed by structural equation modelling and regression analysis. For a subsample $(n=41)$, level of performance was also determined one year later ("future performance level"). Results: Results show that, in contrast to IM $(\mathrm{r}=-.10)$, MCS are positively related to current sport performance level $(\mathrm{r}=.33, p<.05)$. IM is an underlying factor for MCS $(\mathrm{r}=.46, p<.05)$. Regression analyses show that $11 \%$ of variance in current performance level $(p<.05)$ and $18 \%$ in future performance level can be explained by MCS. Conclusion: MCS are positively related to sport performance level in youth athletes, not only in the here and now, but even more over one year. With IM as underlying factor, using MCS and especially reflection, may help youth athletes to improve their sport performance.
\end{abstract}

\section{Keywords}

Talent Development, Psychology, Self-Regulation, Training, Team Sports

\section{Introduction}

To understand talent development and the attainment of excellence, a mul- 
ti-disciplinary approach seems to be essential (Johnston et al., 2018). Multidimensional performance characteristics underpin an athlete's performance level in sports (Elferink-Gemser et al., 2011). They are categorised into anthropological, physiological, technical, tactical and psychological skills (Elferink-Gemser et al., 2004, 2018). With talent development clearly being a multidimensional process, the psychological skills are considered to be a catalyst in reaching elite performance level (MacNamara et al., 2010) as they regulate and facilitate the enhancement of psychological skills that impact upon talent development (Dohme et al., 2017).

Given the necessity to invest the requisite time to practice, to stay committed to the development process and to achieve excellence (Thomas \& Thomas, 1999), it is anticipated that skills underpinning deliberate practice are associated with effective development (Bailey \& Morley, 2006). For example, Gould, Diffenbach and Moffet (2002) imply that Olympic athletes have higher levels of commitment, while they engage in more extensive mental preparation than their novices' peers, skills that are necessary for both the acquisition and manifestation of expertise.

Among the psychological factors, motivation is found to be an important predictor of performance level, especially intrinsic motivation (Pelletier et al., 1995; Cerasoli et al., 2014). Intrinsic motivation is thought to be an important and strong drive in reaching high levels of performance (Moreno et al., 2010). Intrinsic motivation is highly autonomous behaviour to achieve a certain goal (Martens \& Webber, 2002) and can be differentiated into three types of goals to be intrinsically motivated for; intrinsic motivation to know, to perform and to experience (Pelletier et al., 1995). Intrinsic motivation to know can be described as performing an activity for the satisfaction of learning something new. Intrinsic motivation to perform is also known as mastery motivation, task-orientation or efficacy-motivation. This type of intrinsic motivation is driven by the need for competence and satisfaction is derived from accomplishing things. The final type of intrinsic motivation is based on the excitement and enjoyment of experiencing the sensations of an activity (Pelletier et al., 1995).

Various studies have shown a relation between intrinsic motivation and performance level (Deci \& Ryan, 2000; Moreno et al., 2010; Bartholomew et al., 2009), however, less is known about the mechanism. Intriguing questions are: why do athletes who are more intrinsically motivated perform better? Is that because they train more or train more efficiently? The explanation may partly lie in an athlete's use of metacognitive skills. In the sports domain, the use of metacognitive skills has been correlated to the performance level of talented youth athletes (Jonker et al., 2010). Cleary and Zimmerman (2001) identify psychological success skills (e.g., more specific goals, high levels of self-efficacy and other strategies) that distinguished good athletes from the best. Supporting these findings, talented youth athletes have shown to distinguish themselves from their less talented peers by their self-assessed metacognitive skills (Jonker et al., 2010). Further support comes from Toering et al. (2011) implying that self-regulated 
players are more proactive at learning. In addition, metacognition is the awareness and knowledge about ones thinking (Jonker et al., 2011b; Toering et al., 2012). Skills as planning, reflecting and evaluating are considered to be metacognitive and can be seen as a tool to obtain a certain goal for talented youth athletes. This includes determining how to solve a problem before starting (i.e., planning), setting goals to improve based on ones strengths and weaknesses (i.e., reflection), and checking the learning process and the result after execution (i.e., evaluation) (Jonker, 2011a).

In the field of sport performance development, little is known about the exact roles of intrinsic motivation and the use of metacognitive skills in relation to each other and to performance level. In order to spend training time efficiently, insight in factors that relate to the development of sport performance is highly relevant for competitive athletes and their trainers/coaches. Therefore, the overall purpose of the current study was to gain insight into how intrinsic motivation (IM) and the use of metacognitive skills (MCS) correlate to performance level in the here and now and to future performance level in talented youth athletes. Based on previous studies, IM and the use of MCS are hypothesized to play a role in establishing the current and future performance level of youth athletes.

\section{Method}

\subsection{Participants}

For the statistical analyses, the sample size should be 10 observations per variable (Bentler \& Chou, 1987; Bollen, 1989), requiring at least 90 observations for the current study. Because the school requested to include all eligible student-athletes, the final sample consists of 103 participants $(\mathrm{n}=64$ male and $\mathrm{n}=$ 39 female). All participants attended education at the 'Elite Sports Talent' school in Groningen, The Netherlands. This is a secondary school for talented youth athletes, who have a talent or top sport status according to the NOC ${ }^{*} \mathrm{NSF}$ and the relevant sports federation (Stichting Loot, 2019). They were aged between 12 and 17 years (Mage $=13.82, S D=1.37)$ and active in one of 3 team sports: field hockey $(n=11)$, basketball $(n=41)$ and soccer $(n=51)$. They competed at regional $(n=6)$, provincial $(n=7)$, district $(n=24)$, national $(n=63)$ or international level $(\mathrm{n}=3)$. They had a minimum of 3 training hours per week (Mhours $=9.49, \mathrm{SD}=2.62)$ and started with their sport between 3 and 12 years (Mage $=$ $6.49, \mathrm{SD}=2.06)$. Sports performance one year later was monitored for a subsample of $41(\mathrm{n}=27$ male and $\mathrm{n}=14$ female). These participants were aged between 14 and 17 years $\left(\mathrm{M}_{\text {age }}=15.44, \mathrm{SD}=.95\right)$ and divided over the sports: field hockey $(\mathrm{n}=5)$, basketball $(\mathrm{n}=16)$ and soccer $(\mathrm{n}=20)$. They competed at regional $(n=1)$, provincial $(n=3)$, district $(n=9)$, or national level $(n=28)$. They had a minimum of 4 training hours per week $\left(\mathrm{M}_{\text {hours }}=12.01, \mathrm{SD}=3.69\right)$ and started with their sport between 3 and 12 years $\left(\mathrm{M}_{\text {age }}=6.39, \mathrm{SD}=2.13\right)$.

\subsection{Procedures}

Ethical approval was obtained from the university's ethical committee. All par- 
ticipants signed an informed consent form, and at least one parent/guardian signed an informed consent form as well.

Each participant filled in a sport specific questionnaire during school time of approximately 30 minutes. This questionnaire contains general questions about the participants sports history as well as validated sport psychological questionnaires. Data was collected through the online survey program Qualtrics. The questionnaire was compatible for computer, tablet or smartphone. Assistance was present at each testing session by well-trained test leaders to answer questions about the questionnaire in case of indistinctness. Participants who did not fill in at least $75 \%$ of the answers per scale were excluded from further analysis.

\subsection{Performance Level}

To estimate the performance level of the youth athletes a derivative of the proposed formula for "Eliteness"/expertise of athletic sample of Swann, Moran \& Piggott (2015) was used:

[(score athlete's highest standard of performance + score success at the athlete's highest level + score years of experience at the athlete's highest level/2)/3] * [(score competitiveness of sport in athlete's country + score global competitiveness of sport)/2].

This formula is thought to give an indication of the relative performance level of athletes and can be used to compare the performance level of athletes among different sports (Swann et al., 2015). However, using this formula for the youth athletes leads to a few difficulties. Due to the variety in age and starting age the youth athletes are all at different stages of talent development. Therefore, years of experience at highest level and success at highest level are not fair indicators of performance level in this group, since some of the participants are not old enough or did not get the chance to compete at the highest level yet. Based on that the formula was adjusted to give an indication of the "Eliteness"/expertise of the youth athletic sample to:

[("score talented youth athlete's highest standard of performance" + "score training hours per week")/2] $\times$ [("score national competitiveness sport" + "score global competitiveness sport")/2]

The score of the highest standard of performance was based on the highest level of performance the youth athlete competed at. Performing at regional, provincial or district level was awarded 2 points, national level 3 points and international level 4 points as shown in Table 1. Further a score for the training hours per week of the talented youth athletes was included. This is thought to give an indication of the investment in sports (Swann et al., 2015) and talented youth athletes who train more have shown to play at higher competitive level (Elferink-Gemser et al., 2015; Jonker, Elferink-Gemser, Tromp, Baker, \& Visscher, 2015). Scores on the training hours per week were based on the categorization of Jonker et al. (2015): 3 to 6 hours of training per week was awarded 2 points, 6 to 9 hours per week 3 points and 9 or more hours per week 4 points. 
Table 1. For field hockey, basketball and soccer the specific scoring of the athlete specific performance indicators and the National and Global competitiveness are displayed. Higher scores indicate higher levels of performance or competitiveness. These scores are used to calculate the performance level in each youth athlete using the adjusted formula of Swann et al. (2015).

\begin{tabular}{|c|c|c|c|c|c|c|}
\hline & \multicolumn{2}{|c|}{ Field Hockey $(n=11)$} & \multicolumn{2}{|c|}{ Basketball $(\mathrm{n}=41)$} & \multicolumn{2}{|c|}{ Soccer $(n=51)$} \\
\hline & $1=$ & Recreational & $1=$ & Recreational & $1=$ & Recreational \\
\hline \multirow{6}{*}{$\begin{array}{c}\text { Highest } \\
\text { standard of } \\
\text { Performance }\end{array}$} & & Regional, & & Regional, & & Regional, \\
\hline & $2=$ & Provincial & $2=$ & Provincial & $2=$ & Provincial \\
\hline & & or District & & or District & & or District \\
\hline & $3=$ & National & $3=$ & National & $3=$ & National \\
\hline & $4=$ & International & $4=$ & International & $4=$ & International \\
\hline & $1=$ & $<3$ hours & $1=$ & $<3$ hours & $1=$ & $<3$ hours \\
\hline \multirow{3}{*}{$\begin{array}{l}\text { Training } \\
\text { hours } \\
\text { per week }\end{array}$} & $2=$ & $3-6$ hours & $2=$ & $3-6$ hours & $2=$ & 3 - 6 hours \\
\hline & $3=$ & 6 - 9 hours & $3=$ & 6 - 9 hours & $3=$ & 6 - 9 hours \\
\hline & $4=$ & $>9$ hours & $4=$ & $>9$ hours & $4=$ & $>9$ hours \\
\hline $\begin{array}{c}\text { National } \\
\text { competitiveness }\end{array}$ & & 3 points & & 1 point & & 4 points \\
\hline $\begin{array}{c}\text { Global } \\
\text { competitiveness }\end{array}$ & & 2 points & & 4 points & & 4 points \\
\hline
\end{tabular}

The athlete's success at highest level and years of experience at highest level were excluded from the formula.

The score for the competitiveness of a sport in the Netherlands was based the participants register of the year 2016 of the Dutch Olympic committee (NOC * NSF, 2017). Field hockey, basketball and soccer were ranked based on the number of registered participants. According to the formula of Swann et al. (2015) 1 point was awarded for sports ranking outside the national top 10, between top 5 and top 10 a score of 2 points is awarded, between top 2 and top 5 a score of 3 points is awarded, and the national number one sport is awarded with 4 points. Global competitiveness was based on the international popularity of the sport, calculated through the most visited sport news sites of the 16 biggest countries, corrected for the wealth and population of the country (Brown, 2017). Olympic sports, ranking outside the global top 10 (field hockey) was awarded 2 points. Global top 5 sports were awarded 4 points; soccer and basketball.

Based on this formula a score between 1 and 16 was awarded to each talented youth athlete, in which 1 represented a relatively low performance level and 16 very high performance level. For example: a Dutch field hockey player competitive at national level, training 7 hours per week will end up with a score: $((3+$ $3) / 2) \times((3+2) / 2)=7.5$.

\subsection{Instruments}

The Sport Motivation Scale (SMS) was used to measure IM to know, IM to perform and IM to experience. All three variables consist of 4 items scoring on a 
7-point Likert-scale from strongly disagree to strongly agree (Pelletier et al., 1995). Internal consistencies in this sample were .915 for IM to know, .848 for IM to perform and .840 for IM to experience. According to the criterion of .70 (Nunnally, 1978) the Cronbach's coefficients were of sufficient internal consistency.

The frequency of use of reflection, evaluation and planning were collected through the sport specific Self-Regulation of Learning - Self-Report Scale (SRL-SRS) (Toering et al., 2012; Toering, Jordet, \& Ripegutu, 2013) based on Zimmerman's theory about self-regulated learning (Zimmerman, 1989). Reflection (9 items), evaluation (6 items) and planning (7 items) were scored on a 5-point Likert-scale from never to always. The internal consistencies in this sample for reflection were .865 , for evaluation .870 and for planning .785 . According to the criterion of .70 (Nunnally, 1978) the Cronbach's coefficients were of sufficient internal consistency.

\subsection{Data Analysis}

Data was collected in IBM SPSS Statistics 23. Mean scores, standard deviations and correlation matrices were calculated using SPSS for the use of metacognitive skills (reflection, evaluation and planning), IM (-to know, -to perform and -to experience) and performance level.

The hypothetical model was based on theory from literature. IM to know, -to perform and -to experience are expected to load on to IM (Pelletier et al., 1995). IM is hypothesized to be positively correlated to the use of metacognitive skills (Bartholomew et al., 2009; Deci \& Ryan, 2000; Moreno et al., 2010). Metacognitive skills consist of reflection, evaluation and planning (Jonker, 2011a).

LISREL 8.80 (Jöreskog \& Sörbom, 1993) was used to test the hypothetical model. LISREL is specially designed for estimating the coefficients of structural equations. In structural equation modelling it is assumed that the parameters have kind of a causal relationship instead of being descriptive measures of association. This does not mean that LISREL is able to discover causal relationships, but the program is able to show if the assumed causal relationships match the data (Bollen, 1989). Using a correlation matrix LISREL calculates estimates of the coefficients for the relationships between dependent and independent variables, estimates for the relationships between dependent variables and estimates for the variances of the residuals of the dependent variables.

The goodness of fit of the model was assessed using the Minimum Fit Function Chi-Square (MFF $\mathrm{X}_{2}$ ), the Standardised Root Mean Residual (SRMR), the Goodness of Fit Index (GFI) and the root mean square error of approximation (RMSEA). MFF $\mathrm{X}_{2}$ displays the fit of the model to the data and should not be significant $(p>.05)$, since significance would mean that the model differs from the data (Barrett, 2007). The SRMR displays the square root of the difference between the residuals of the sample matrix and the hypothesised model. The SRMR standardises the ranges of the questionnaires, making it more meaningful to interpret. The SRMR ranges from 0 to 1 and should not exceed .05 (Byrne, 
1998; Diamantopoulos \& Siguaw, 2000). The GFI was created by Jöreskog \& Sörbom as an alternative for the Chi-square and calculates the proportion of variance that is accounted for by the estimated population covariance (Tabachnick et al., 2007), it gives an indication of how accurate the model replicates the observed covariance matrix. The GFI should exceed .95 (Shevlin \& Miles, 1998). The RMSEA takes into account the error of approximation and is one of the most informative criteria in covariance structure modelling (Byrne, 1998). Values below 0.08 indicate a reasonable error of approximation, values below 0.05 are considered good fit (Jöreskog \& Sörbom, 1993).

To analyse the second aim of the study for a subsample $(n=41)$, one correlation and multiple regression analysis were conducted to examine the relationship between baseline performance level and metacognitive skills as potential predictors, and a second correlation and multiple regression analysis were conducted to examine the relationship between future performance level (+1 year) and the baseline measured metacognitive skills as potential predictors. The outcomes of both regression analyses were compared.

\section{Results}

Table 2 shows the mean scores and standard deviations for intrinsic motivation to know, -to perform, -to experience, the use of reflection, evaluation and planning and performance level of the talented youth athletes.

Table 3 shows the correlations between the variables used in the analysis. The hypothetical model is displayed in Figure 1. The model fits the data well $\operatorname{MFF~X}_{2}(13)=19.67, p=.11, \mathrm{SRMR}=.048$, GFI $=.95$, RMSEA $=0.075$. IM was indicated by IM to know $(.87, p<.05)$, IM to perform $(.94, p<.05)$ and IM to experience $(.82, p<.05)$. The use of MCS was indicated by reflection $(.97, p$ $<.05)$, evaluation $(.82, p<.05)$ and planning $(.66, p<.05)$. Structural equations

Table 2. Descriptive statistics (mean scores, Std) of intrinsic motivation, use of metacognitive skills and current performance level of talented youth athletes $(n=103)$. Higher scores indicate higher levels.

\begin{tabular}{lcc}
\hline \multicolumn{1}{c}{ Maximal range } & $\begin{array}{c}\text { Mean } \\
(\mathrm{n}=103)\end{array}$ & Std \\
\hline Intrinsic motivation & & \\
- To know $(1-7)$ & 5.37 & 1.05 \\
- To perform $(1-7)$ & 5.30 & 0.95 \\
- To experience $(1-7)$ & 5.37 & 0.95 \\
$\quad$ Use of Meta-cognitive skills & & \\
- Reflection $(1-5)$ & 3.40 & 0.60 \\
- Evaluation $(1-5)$ & 3.22 & 0.71 \\
Planning $(1-5)$ & 2.80 & 0.62 \\
Current performance level $(1-16)$ & 9.73 & 2.16
\end{tabular}


Table 3. Correlation matrix with two-tailed significance of the variables included in the analysis: Intrinsic Motivation (IM) to know, IM to perform, IM to experience, reflection, evaluation, planning and current performance level in talented youth athletes $(\mathrm{n}=103)$.

\begin{tabular}{|c|c|c|c|c|c|c|c|}
\hline & IM to know & IM to perform & IM to experience & Reflection & Evaluation & Planning & $\begin{array}{c}\text { Current } \\
\text { performance level }\end{array}$ \\
\hline IM to know & 1 & & & & & & \\
\hline IM to perform & $.815^{\star *}(.000)$ & 1 & & & & & \\
\hline IM to experience & $.704^{\star \star}(.000)$ & $.777^{\star \star}(.000)$ & 1 & & & & \\
\hline Reflection & $.459^{* *}(.000)$ & $.408^{\star *}(.000)$ & $.390^{* *}(.000)$ & 1 & & & \\
\hline Evaluation & $.328^{\star \star}(.001)$ & $.294^{\star *}(.003)$ & $.328^{* *}(.001)$ & $.791^{\star *}(.000)$ & 1 & & \\
\hline Planning & $.114(.250)$ & $.174(.078)$ & $.220^{*}(.025)$ & $.633^{\star *}(.000)$ & $.576^{* \star}(.000)$ & 1 & \\
\hline $\begin{array}{c}\text { Current } \\
\text { performance level }\end{array}$ & $.098(.326)$ & $.042(.673)$ & $\begin{array}{c}.123 \\
(.215)\end{array}$ & $.316^{\star *}(.001)$ & $.265^{\star \star}(.007)$ & $.290^{\star *}(.003)$ & 1 \\
\hline
\end{tabular}

${ }^{*} p<.05$ (two-tailed), ${ }^{* *} p<.01$ (two-tailed).

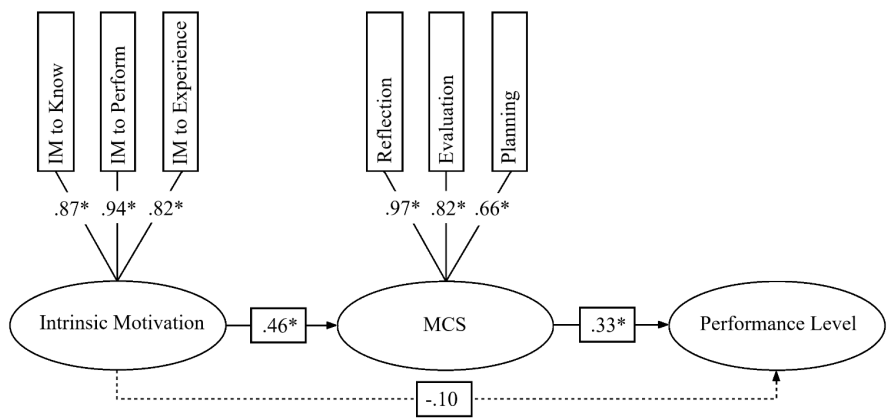

Figure 1. Hypothetical model displaying the structural equation modelling. Significant correlations between intrinsic motivation (IM); indicated by IM to know, IM to perform and IM to experience, the use of metacognitive skills (MCS); indicated by reflection, evaluation and planning and current performance level $(p<.05)$. Intrinsic motivation to current performance level was not significant $\left(p>.05\right.$.) Model fit: $\operatorname{MFF} \mathrm{X}^{2}(13)=19.67, p$ $=.11, \mathrm{SRMR}=.048, \mathrm{GFI}=.95, \mathrm{RMSEA}=0.075 .{ }^{\star} p<.05$.

between IM and use of MCS $(.46, p<.05)$ and between the use of MCS and performance level $(.33, p<.05)$ were significant but not between IM and performance level $(-.10, p>.05)$. An additional analysis was performed to test whether IM was directly related to performance level. The model significantly differed

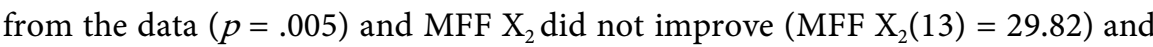
therefore this adjustment was rejected. IM and MCS both as a separate correlation to performance level and not correlated to each other did also not significantly improve the model $\left(\operatorname{MFF} \mathrm{X}_{2}(12)=18.96, \mathrm{MFF}_{2}\right.$ difference $\left.(1)<3.84\right)$. Although the model did fit the data $(p=.09)$, the correlation from IM to performance was not significant and the adjustment was rejected.

The multiple regression model for current performance level with MCS as predictors resulted in $\mathrm{R}^{2}=.112, \mathrm{~F}(3,99)=4.147, p=.008$. Table 4 shows the statistics regarding the relation between MCS and future performance level. The multiple regression model for future performance level with MCS as predictors resulted in $\mathrm{R}^{2}=.180, \mathrm{~F}(3,37)=2.704, p=.059$. 
Table 4. Summary statistics, correlations and results from the regression analysis of the future performance level $(\mathrm{n}=41)$.

\begin{tabular}{ccccccc}
\hline \multicolumn{7}{c}{ Multiple Regression } \\
\hline Variable & Mean & Std & $\begin{array}{c}\text { Correlation with future } \\
\text { performance level }\end{array}$ & $\mathrm{b}$ & $\beta$ \\
\hline $\begin{array}{c}\text { Future performance level } \\
(+1 \text { year })\end{array}$ & 10.59 & 2.62 & & & & \\
Reflection & 3.31 & .63 & $.405^{* *}$ & 1.051 & .255 \\
Evaluation & 3.10 & .72 & $.352^{*}$ & .329 & .090 \\
Planning & 2.62 & .62 & $.254^{*}$ & .533 & .126 \\
\hline${ }^{*} p<.05,{ }^{* *} p<.01$. & & & & &
\end{tabular}

\section{Discussion}

The aim of this study was to investigate how intrinsic motivation and the use of MCS correlate to performance level in youth athletes, measuring IM to know, IM to perform, IM to experience and reflection, evaluation, planning, respectively. The study unravels part of the mechanism explaining performance and the development thereof. The results reveal significant positive relations between IM, and the use of MCS. As expected, a significant positive relation was also apparent between the use of MCS and performance level in talented youth athletes. In contrast, IM seems to have an indirect effect only on the performance level of youth athletes through using metacognitive skills. It seems that the more intrinsically motivated a youth athlete is, the more metacognitively proactive, and the higher level of athletic goals he accomplishes. In accordance with this, the results show that a youth athlete's use of metacognitive skills is even a better predictor of the second year of performance comparing to the first. Especially reflection seems to be a relevant indicator of future performance.

The first part of the study investigated how IM coheres with the frequency of use of MCS, and how this is related to the performance level of youth athletes. The results clearly show the complexity of the relations between psychological constructs and performance level. Although previous studies have shown that athletes performing at a higher performance level outscore their less-performing counterparts on motivation (e.g., Durand-Bush \& Salmela, 2002; Gould, Dieffenbach \& Moffett, 2002; Orlick \& Partington, 1998), the current study disputes a direct relation. The results indicate that IM alone is not enough to warrant high performance level. Rather, a correlation between IM and MCS has been shown. The better performing athletes report a higher frequency of use of MCS and as such seem to more often take action in order to improve their performance level than the less performing ones. This is supported by the positive and significant relation between the frequency of use of MCS with performance in the structural equation model.

The scores on IM to know, to perform and to experience of the youth athletes in the current study are relatively high compared to other studies (Ntoumanis, 
2001; Pelletier et al., 1995), which seems logical considering the characteristics of the population. All youth athletes regard their performance level very important and they work on improving that on a daily basis. IM in sports is an internal endeavor towards knowing, performing or experiencing (Pelletier et al., 1995). It gives direction to the behavior and quantifies the importance of such a goal (i.e. knowing, performing or experiencing) for the youth athlete. However, IM does not provide a very specific and objective goal to direct specific behavior. The use of MCS differs from IM in goal-orientated behavior by accurately specifying the goal. In order to fulfill the desire to know, to perform or to experience, a youth athlete must practice his or her sport-specific skills (Elferink-Gemser et al., 2011). By using MCS, such as reflection, evaluation and planning, talented youth athletes can learn and train sport-specific skills and improve their performance level efficiently (Jonker et al., 2011a). More use of MCS is correlated to a higher performance level (Cleary \& Zimmerman, 2001; Jonker et al., 2010).

The youth athletes in the current study scored highest on the use of reflection when compared to the other MCS, which is in line with earlier research demonstrating that expert performance level athletes outscore their non-expert peers significantly on reflection (Jonker, Elferink-Gemser, \& Visscher, 2011b). The current study shows that reflection scores are more strongly related to future performance level than to performance level in the here and now ( $\mathrm{r}=.41 \mathrm{vs} \mathrm{r}$ $=.32$ ). Jonker and colleagues (2012) also emphasized the value of reflection for future performance level. Youth expert level athletes who eventually reached senior international level demonstrated higher reflection scores than the youth expert level athletes who did not reach senior international level (Jonker et al., 2012). Therefore, trainers and coaches are advised to stimulate the use of reflection in their athletes. They can use their reflection skills while taking the pathway towards expertise which is considered to be challenging, complex, and dynamic (Henriksen, Stambulova, \& Roessler, 2010; MacNamara et al., 2010). An interesting venue for further research is to study the actual behavior of the youth athletes and relate this to their performance level and performance improvement (Blijlevens, Elferink-Gemser, Wylleman, Bool, \& Visscher, 2018).

This study does have limitations. There was some loss in the sample size in the second year that may have lead to bias, since some have suggested that $<5 \%$ loss leads to little bias, while $>20 \%$ leads to serious threats to validity (Satya-Murti, 2000). Moreover, as it is common in this kind of studies, we used a self-report questionnaire that is sensitive to social desirable answers (Ericsson et al., 1993; Young \& Starkes, 2006). Furthermore, the way we determined performance level is not validated yet, since it has never been applied before. To further unravel the mystery of expertise, we recommend assessing the performance level as well as self-regulation of individual athletes as well.

The aim of this study was to unravel the value of IM and the use of MCS for current and future performance level in youth athletes. After conducting structural equation modelling and multiple regression, it became clear that the use of MCS is positively related to current as well as future sport performance level in 
youth athletes. It can be concluded that IM acts as underlying factor while the use of MCS, especially reflection, can explain part of the performance differences in youth athletes. This contributes to the belief that MCS play an important role in reaching higher performance levels. Therefore, MCS are considered important in talent development which should be recognized by trainers and coaches of youth athletes.

\section{Acknowledgements}

We thank all talented athletes for their participation in this study, as well as the school for their assistance in organizing the measurements. Special thanks go to the Bachelor and master students for their help in gathering the data.

\section{Conflicts of Interest}

The authors declare no conflicts of interest regarding the publication of this paper.

\section{References}

Bailey, R., \& Morley, D. (2006). Towards a Model of Talent Development in Physical Education. Sport, Education and Society, 11, 211-230. https://doi.org/10.1080/13573320600813366

Barrett, P. (2007). Structural Equation Modelling: Adjudging Model Fit. Personality and Individual Differences, 42, 815-824. https://doi.org/10.1016/j.paid.2006.09.018

Bartholomew, K. J., Ntoumanis, N., \& Thøgersen-Ntoumani, C. (2009). A Review of Controlling Motivational Strategies from a Self-Determination Theory Perspective: Implications for Sports Coaches. International Review of Sport and Exercise Psychology, 2, 215-233. https://doi.org/10.1080/17509840903235330

Bentler, P. M., \& Chou, C. H. (1987). Practical Issues in Structural Modelling. Sociological Methods \& Research, 16, 78-117. https://doi.org/10.1177/0049124187016001004

Blijlevens, S. J. E., Elferink-Gemser, M. T., Wylleman, P., Bool, K., \& Visscher, C. (2018). Psychological Characteristics and Skills of Top-Level Dutch Gymnasts in the Initiation, Development and Mastery Stages of the Athletic Career. Psychology of Sport and Exercise, 38, 202-210. https://doi.org/10.1016/j.psychsport.2018.07.001

Bollen, K. A. (1989). Structural Equations with Latent Variables. New York: Wiley \& Sons. https://doi.org/10.1002/9781118619179

Brown, M. (2017). Biggest Global Sports-A Statistics-Based Analysis of the Biggest Global Sports. http://www.biggestglobalsports.com/worlds-biggest-sports/4580873435

Byrne, B. M. (1998). Structural Equation Modelling with LISREL, PRELIS and SIMPLIS: Basic Concepts, Applications and Programming. Mahwah, NJ: Lawrence Erlbaum Associates.

Cerasoli, C. P., Nicklin, J. M., \& Ford, M. T. (2014). Intrinsic Motivation and Extrinsic Incentives Jointly Predict Performance: A 40-Year Meta-Analysis. Psychological Bulletin, 140, 980-1008. https://doi.org/10.1037/a0035661

Cleary, T. J., \& Zimmerman, B. J. (2001). Self-Regulation Differences during Athletic Practice by Experts, Non-Experts, and Novices. Journal of Applied Sport Psychology, 13, 185-206. https://doi.org/10.1080/104132001753149883

Deci, E. L., \& Ryan, R. M. (2000). Intrinsic and Extrinsic Motivations: Classic Definitions 
and New Directions. Contemporary Educational Psychology, 25, 54-67. https://doi.org/10.1006/ceps.1999.1020

Diamantopoulos, A., \& Siguaw, J. A. (2000). Introducing LISREL. London: Sage Publications. https://doi.org/10.4135/9781849209359

Dohme, L. C., Backhouse, S., Piggott, D., \& Morgan, G. (2017). Categorising and Defining Popular Psychological Terms Used within the Youth Athlete Talent Development Literature: A Systematic Review. International Review of Sport and Exercise Psychology, 10, 134-163. https://doi.org/10.1080/1750984X.2016.1185451

Durand-Bush, N., \& Salmela, J. H. (2002). The Development and Maintenance of Expert Athletic Performance: Perceptions of World and Olympic Champions. Journal of Applied Sport Psychology, 14, 154-171. https://doi.org/10.1080/10413200290103473

Elferink-Gemser, M. T., De Roos, I., Torenbeek, M., Fokkema, T., Jonker, L., \& Visscher, C. (2015). The Importance of Psychological Constructs for Training Volume and Performance Improvement. A Structural Equation Model for Youth Speed Skaters. International Journal of Sport Psychology, 46, 726-744.

Elferink-Gemser, M. T., Jordet, G., Coelho-E-Silva, M. J., \& Visscher, C. (2011). The Marvels of Elite Sports: How to Get There? British Journal of Sports Medicine, 45, 683. https://doi.org/10.1136/bjsports-2011-090254

Elferink-Gemser, M. T., Te Wierike, S., \& Visscher, C. (2018). Multidisciplinary, Longitudinal Studies: A Perspective from the Field of Sports. In K. A. Ericsson, R. Hoffman, A. Kozbelt, \& M. Williams (Eds.), The Cambridge Handbook of Expertise and Expert Performance (2nd ed., pp. 271-290). Cambridge: Cambridge University Press.

Elferink-Gemser, M., Visscher, C., Lemmink, K., \& Mulder, T. (2004). Relation between Multidimensional Performance Characteristics and Level of Performance in Talented Youth Field Hockey Players. Journal of Sports Sciences, 22, 1053-1063. https://doi.org/10.1080/02640410410001729991

Ericsson, K. A., Krampe, R. T., \& Tesch-Römer, C. (1993). The Role of Deliberate Practice in the Acquisition of Expert Performance. Psychological Review, 100, 363. https://doi.org/10.1037/0033-295X.100.3.363

Gould, D., Dieffenbach, K., \& Moffett, A. (2002). Psychological Characteristics and Their Development in Olympic Champions. Journal of Applied Sport Psychology, 14, 172-204. https://doi.org/10.1080/10413200290103482

Henriksen, K., Stambulova, N., \& Roessler, K. K. (2010). Holistic Approach to Athletic Talent Development Environments: A Successful Sailing Milieu. Psychology of Sport and Exercise, 11, 212-222. https://doi.org/10.1016/j.psychsport.2009.10.005

Johnston, K., Wattie, N., Schorer, J., \& Baker, J. (2018). Talent Identification in Sport: A Systematic Review. Sports Medicine, 48, 97-109.

https://doi.org/10.1007/s40279-017-0803-2

Jonker, L., Elferink, M. T., Yvonne Tromp, E. J., Baker, J., \& Visscher, C. (2015). Psychological Characteristics and the Developing Athlete. In J. Baker, \& D. Farrow (Eds.), Routledge Handbook of Sport Expertise (pp. 317-328). UK: Routledge. https://doi.org/10.4324/9781315776675-28

Jonker, L., Elferink-Gemser, M. T., \& Visscher, C. (2011a). The Role of Self-Regulatory Skills in Sport and Academic Performances of Elite Youth Athletes. Talent Development \& Excellence, 3, 263-275.

Jonker, L., Elferink-Gemser, M. T., \& Visscher, C. (2011b). The Role of Self-Regulatory Skills in Sports and Academia: A Systematic Review. Talent Development and Excellence, 3, 263-275. 
Jonker, L., Elferink-Gemser, M. T., de Roos, I. M., \& Visscher, C. (2012). The Role of Reflection in Sport Expertise. Sport Psychologist, 26, 224-242. https://doi.org/10.1123/tsp.26.2.224

Jonker, L., Elferink-Gemser, M., \& Visscher, C. (2010). Differences in Self-Regulatory Skills among Talented Athletes: The Significance of Competitive Level and Type of Sport. Journal of Sports Sciences, 28, 901-908. https://doi.org/10.1080/02640411003797157

Jöreskog, K. G., \& Sörbom, D. (1993). LISREL 8: Structural Equation Modeling with the SIMPLIS Command Language Chicago, IL: Scientific Software International.

MacNamara, A., Button, A., \& Collins, D. (2010). The Role of Psychological Characteristics in Facilitating the Pathway to Elite Performance Part 1: Identifying Mental Skills and Behaviours. Sport Psychologist, 24, 52-73. https://doi.org/10.1123/tsp.24.1.52

Martens, M. P., \& Webber, S. N. (2002). Psychometric Properties of the Sport Motivation Scale: An Evaluation with College Varsity Athletes from the U.S. Journal of Sport \& Exercise Psychology, 24, 254-270. https://doi.org/10.1123/jsep.24.3.254

Moreno, J. A., Cervello, E., \& Gonzalez-Cutre, D. (2010). The Achievement Goal and Self-Determination Theories as Predictors of Dispositional Flow in Young Athletes. Anales de Psicologia, 26, 390-399.

Ntoumanis, N. (2001). Empirical Links between Achievement Goal Theory and Self-Determination Theory in Sport. Journal of Sports Sciences, 19, 397-409. https://doi.org/10.1080/026404101300149357

Nunnally, J. C. (1978). Psychometric Theory(2nd ed.). New York: McGraw-Hill.

Orlick, T., \& Partington, J. (1998). Mental Links to Excellence. The Sport Psychologist, 2, 105-130. https://doi.org/10.1123/tsp.2.2.105

Pelletier, L. G., Tuson, K. M., Fortier, M. S., Vallerand, R. J., Briére, N. M., \& Blais, M. R. (1995). Toward a New Measure of Intrinsic Motivation, Extrinsic Motivation, and Amotivation in Sports: The Sport Motivation Scale (SMS). Journal of Sport and Exercise Psychology, 17, 35-53. https://doi.org/10.1123/jsep.17.1.35

Satya-Murti, S. (2000). Evidence-Based Medicine: How to Practice and Teach EBM. JAMA, 284, 2382-2383. https://doi.org/10.1001/jama.284.18.2382

Shevlin, M., \& Miles, J. N. V. (1998). Effects of Sample Size, Model Specification and Factor Loadings on the GFI in Confirmatory Factor Analysis. Personality and Individual Differences, 25, 85-90. https://doi.org/10.1016/S0191-8869(98)00055-5

Stichting Loot (2019). Stichting Loot. http://www.stichtingloot.nl/

Swann, C., Moran, A., \& Piggott, D. (2015). Defining Elite Athletes: Issues in the Study of Expert Performance in Sport Psychology. Psychology of Sport \& Exercise, 16, 3-14. https://doi.org/10.1016/j.psychsport.2014.07.004

Tabachnick, B. G., Fidell, L. S., \& Ullman, J. B. (2007). Using Multivariate Statistics (Vol. 5). Boston, MA: Pearson.

Thomas, K. T., \& Thomas, J. R. (1999). What Squirrels in the Trees Predict about Expert Athletes. International Journal of Sport Psychology, 30, 221-234.

Toering, T., Elferink-Gemser, M., Jonker, L., van Heuvelen, M. J. G., \& Visscher, C. (2012). Measuring Self-Regulation in a Learning Context: Reliability and Validity of the Self-Regulation of Learning Self-Report Scale (SRL-SRS). International Journal of Sport and Exercise Psychology, 10, 24-38. https://doi.org/10.1080/1612197X.2012.645132

Toering, T., Elferink-Gemser, M., Jordet, G., Jorna, C., Pepping, G. J., \& Visscher, C. (2011). Self Regulation of Practice Behavior among Elite Youth Soccer Players: An Exploratory Observation Study. Journal of applied Sport Psychology, 23, 110-128. 
https://doi.org/10.1080/10413200.2010.534544

Toering, T., Jordet, G., \& Ripegutu, A. (2013). Effective Learning among Elite Football Players: The Development of a Football-Specific Self-Regulated Learning Questionnaire. Journal of Sports Sciences, 31, 1412-1420. https://doi.org/10.1080/02640414.2013.792949

Young, B. W., \& Starkes, J. L. (2006). Measuring Outcomes of Swimmers' Non-Regulation during Practice: Relationships between Self-Report, Coaches' Judgments, and Video-Observation. International Journal of Sports Science \& Coaching, 1, 131-148. https://doi.org/10.1260/174795406777641320

Zimmerman, B. J. (1989). A Social Cognitive View of Self-Regulated Academic Learning. Journal of Educational Psychology, 81, 329-339.

https://doi.org/10.1037/0022-0663.81.3.329 